Pacific Journal of Mathematic 


\title{
CONDITIONS UNDER WHICH A CONNECTED REPRESENTABLE SPACE IS LOCALLY CONNECTED
}

\author{
P. Fletcher and R. A. MCCoy
}

In this paper it is shown that every strongly locally homogeneous Hausdorff continuum is locally connected. It is known that every connected representable space is homogeneous and that every locally connected representable space is strongly locally homogeneous; this paper investigates the problem of whether or not every connected representable space is locally connected.

The discovery that homogeneity did not characterize the circle among planar continua motivated other classifications of continua in terms of the actions of their homeomorphism groups, and the pseudoarc remains the most tortuous proving grounds for testing such topological properties. Those homogeneity-like properties that are not possessed by the pseudo-arc appear to be closely related to local connectedness. Such properties include strong local homogeneity, representability, (strong) 2-homogeneity and countable dense homogeneity.

In this paper it is shown that every strongly locally homogeneous Hausdorff continuum is locally connected. It is known that every connected representable space is homogeneous and that every locally connected representable space is strongly locally homogeneous; this paper investigates the problem of whether or not every connected representable space is locally connected. It follows from results of Ben Fitzpatrick, Jr. and Ralph Bennett that every connected locally compact separable metric representable space is locally connected. Arguments of Fitzpatrick and de Groot are used to show that if $(X, \tau)$ is a representable connected complete metric space such that $\tau$ does not have a base of totally disconnected sets, then $(X, \tau)$ is locally connected (and hence arcwise connected and strongly locally homogeneous). The authors do not know of even a homogeneous connected complete metric space with a base of totally disconnected sets; however, there exists a separable connected metric topology that has such a base.

Let $(X, \tau)$ be a topological space. We let $H(X)$ denote the group of all homeomorphisms from the space $(X, \tau)$ onto itself and let $i$ denote the identity of $H(X)$. If $A \subset X$, then $A^{\prime}=\{h \in H(X): h \mid A=$ $i \mid A\}$ and if $G$ is a subgroup of $H(X)$, then $G^{\prime}=\{x \in X: g(x)=x$ for each $g \in G\}$. If $G \subset H(X)$ and $A \subset X$, then $G(A)=\{g(a): g \in G$ and $a \in A\}$. We write $G(x)$ in room of $G(\{x\})$. Throughout this paper all spaces are assumed to be Hausdorff. 
DEFINITION [5]. A topological space $(X, \tau)$ is representable provided that for every neighborhood $U$ of any point $x \in X$, there exists a subneighborhood $V$ such that if $y \in V$, then there is $h \in(X-U)^{\prime}$ such that $h(x)=y$.

DEFINITION [7]. A topological space $(X, \tau)$ is strongly locally homogeneous provided that for every neighborhood $U$ of any point $x \in X$, there exists a subneighborhood $V$ such that if $y \in V$, then there is $h \in(X-V)^{\prime}$ such that $h(x)=y$.

It is known that a topological space $(X, \tau)$ is representable if and only if for each closed set $F$ and each $x \in X-F, F^{\prime}(x) \in \tau$ [5, Corollary to Theorem 1].

Lemma [6, Lemma 4.3]. Let $(X, \tau)$ be a representable continuum, let $F$ be a closed subset of $X$ and let $x \in X-F$. Then $\overline{F^{\prime \prime}(x)}$ is a subcontinuum of $X$ with interior points.

Proposition 1. Every representable continuum is locally connected.

Proof. Let $(X, \tau)$ be a representable continuum and let $x \in U \in \tau$. Since $(X, \tau)$ is homogeneous it suffices to show that $(X, \tau)$ is connected im kleinen at $x$. Since $(X, \tau)$ is compact and Hausdorff, there is an open set $V$ such that $x \in V \subset \bar{V} \subset U$. Let $F=X-V$. By the preceding lemma, $\overline{F^{\prime \prime}(x)}$ is connected and since $F^{\prime \prime}(x) \subset V, \overline{F^{\prime}(x)} \subset \bar{V} \subset U$. Since $(X, \tau)$ is representable $F^{\prime}(x) \in \tau$ and hence $(X, \tau)$ is connected im kleinen at $x$.

COROLLARY. Every representable continuum is strongly locally homogeneous.

Proof. [6, Theorem 2.4].

DEFINITION [2]. A separable topological space $(X, \tau)$ is countable dense homogeneous provided that for any two countable dense subsets $M$ and $N$ of $X$ there exists $h \in H(X)$ such that $h(M)=N$.

We have need of an amalgam of the following two theorems proved by R. Bennett and J. de Groot respectively.

TheOREM 2 [2, Theorem 3]. Every locally compact separable representable metric space is countable dense homogeneous.

TheOREM 3 [8, Theorem 1]. Every separable strongly locally homogeneous complete metric space is countable dense homogeneous. 
We have been unable to show that every representable space is strongly locally homogeneous, however strong local homogeneity can be replaced by representability in the above theorem; and for the sake of completeness we give a proof of this perhaps more general result, based on J. de Groot's arguments.

Lemma [1, page 777 and 8, page 3]. Let $(X, \rho)$ be a complete metric space, and let $\left\{\varphi_{n}\right\}_{n=1}^{\infty}$ be a sequence of homeomorphisms from $X$ onto itself. If, for every positive integer $n$ and every $x \in X, \rho\left(\varphi_{n}(x), \varphi_{n+1}(x)\right)<1 / 2^{n}$ and $\rho\left(\varphi_{n}^{-1}(x), \varphi_{n+1}^{-1}(x)\right)<1 / 2^{n}$, then $\left\{\varphi_{n}\right\}_{n=1}^{\infty}$ converges to a homeomorphism from $X$ onto itself.

THEOREM 4. Every separable representable complete metric space is countable dense homogeneous.

Proof. Let $(X, \rho)$ be a separable complete metric space that is representable and let $A=\left\{a_{n}\right\}_{n=1}^{\infty}$ and $B=\left\{b_{n}\right\}_{n=1}^{\infty}$ be countable dense subsets of $X$. Let $V_{1}$ be an open set containing $b_{1}$ and contained in $B\left(b_{1}, 1 / 4\right)$ such that for every $x \in V_{1}$ there exists $f \in\left(X-B\left(b_{1}, 1 / 4\right)\right)^{\prime}$ with $f(x)=b_{1}$. Let $k(1)$ be the least positive integer such that $a_{k(1)} \in$ $V_{1}$. Let $f_{1} \in\left(X-B\left(b_{1}, 1 / 4\right)\right)^{\prime}$ such that $f_{1}\left(a_{k(1)}\right)=b_{1}$. For each $j$ such that $0<j<k(1)$, if any such $j$ exists, define $U_{1}^{j}, V_{1}^{j}, p(1, j)$, and $g_{1, j}$ as follows. Let $U_{1}^{j}$ be pairwise disjoint open sets such that $a_{j} \in U_{1}^{j} \subset$ $B\left(a_{j}, 1 / 4\right)-\left\{b_{1}\right\}$. Let $V_{1}^{j}$ be open sets such that $a_{j} \in V_{1}^{j} \subset U_{1}^{j}$ and for every $x \in V_{1}^{j}$ there exists $f \in\left(X-U_{1}^{j}\right)^{\prime}$ with $f\left(a_{j}\right)=x$. Since $B$ is dense in $X$, there exist distinct integers $p(1, j)>1$ such that $b_{p(1, j)} \in V_{1}^{j}$. Then there are $g_{1, j} \in\left(X-U_{1}^{j}\right)^{\prime}$ with $g_{1, j}\left(a_{j}\right)=b_{p(1, j)}$. Define $h_{1}$ to be $g_{1, k(1)-1} \circ g_{1, k(1)-2} \cdots \circ g_{1,1} \circ f_{1}\left(\right.$ or $h_{1}=f_{1}$ if $\left.k(1)=1\right)$, and set $\varphi_{1}=h_{1}, m(1)=1$ and $k(0)=0$.

Define $\varphi_{n+1}$ be induction as follows. Let $m(n+1)$ be the least integer that is greater than $m(n)$ and not equal to $p(i, j)$ for any $1 \leqq i \leqq n$ and $k(i-1)<j<k(i)$. Set $b=b_{m(n+1)}$ and $Y=\left\{b_{m(i)}: 1 \leqq\right.$ $i \leqq n\} \cup\left\{a_{k(i)}: 1 \leqq i \leqq n\right\} \cup\left\{a_{j}: 1 \leqq i \leqq n, k(i-1)<j<k(i)\right\} \cup\left\{b_{p(i, j)}: 1 \leqq\right.$ $i \leqq n, k(i-1)<j<k(i)\}$. Let $\varepsilon>0$ be such that $B(b, \varepsilon) \subset\left(B\left(b, 1 / 2^{n+2}\right) \cap\right.$ $\left.\varphi_{n}\left[B\left(\varphi_{n}^{-1}(b), 1 / 2^{n+1}\right)\right]\right)-Y$. Let $V_{n+1}$ be an open set containing $b$ and contained in $B(b, \varepsilon / 3)$ such that for every $x \in V_{n+1}$ there exists $f \in$ $(X-B(b, \varepsilon / 3))^{\prime}$ with $f(x)=b$. Let $k(n+1)$ be the least integer greater than $k(n)$ such that $a_{k(n+1)} \in V_{n+1}$. Let $f_{n+1} \in(X-B(b, \varepsilon / 3))^{\prime}$ such that $f_{n+1}\left(a_{k(n+1)}\right)=b$. For every $j$ such that $k(n)<j<k(n+1)$, if any such $j$ exists, define $U_{n+1}^{j}, V_{n+1}^{j}, p(n+1, j)$, and $g_{n+1, j}$ as follows. Let $U_{n+1}^{j}$ be pairwise disjoint open sets such that $a_{j} \in U_{n+1}^{j} \subset\left(B\left(a_{j}, \varepsilon / 3\right)\right) \cap$ $\varphi_{n}\left[B\left(\varphi_{n}^{-1}\left(a_{j}, 1 / 2^{n+1}\right)\right]\right)-(Y \cup\{b\})$. Let $V_{n+1}^{j}$ be open sets such that $a_{j} \in V_{n+1}^{j} \subset U_{n+1}^{j}$ and such that for every $x \in V_{n+1}^{j}$, there is $f \in\left(X-U_{n+1}^{j}\right)^{\prime}$ with $f\left(a_{j}\right)=x$. Since $B$ is dense in $X$, there exist distinct integers 
$p(n+1, j)$ which are greater than $m(n+1)$ and not equal to $p(i, j)$ for $1 \leqq i \leqq n$ and $k(i-1)<j<k(i)$ such that $b_{p(n+1, j)} \in V_{n+1}^{j}$. Then there are $g_{n+1, j} \in\left(X-U_{n+1}^{j}\right)^{\prime}$ with $g_{n+1, j}\left(a_{j}\right)=b_{p(n+1, j)}$. Define $h_{n+1}=$ $g_{n+1, k(n+1)-1} \circ g_{n+1, k(n+1)-2} \circ \cdots g_{n+1, k(n)+1} \circ f_{n+1}\left(\right.$ or $h_{n+1}=f_{n+1}$ if $k(n+1)=$ $k(n)+1)$. Finally let $\varphi_{n+1}=h_{n+1} \circ \varphi_{n}$.

The sequence $\left\{\Phi_{n}\right\}_{n=1}^{\infty}$ defined above satisfies the hypothesis of the lemma. Then if $\varphi=\lim \varphi_{n}, \varphi \in H(X)$ such that $\varphi(A)=B$. Therefore, $X$ is countable dense homogeneous.

It is known that every locally compact connected metric countable dense homogeneous space is locally connected [4, Theorem 1]. Consequently every metric locally compact separable connected representable space is locally connected. As in the proof of Theorem 1 of [4], we note that if $(X, \tau)$ is a separable countable dense homogeneous complete metric space such that every nonempty open set contains a nondegenerate connected set, then $(X, \tau)$ is locally connected. Moreover, if a representable space $(X, \tau)$ has a totally disconnected open subset, then $\tau$ has a base of totally disconnected sets. Thus we have the following proposition:

PRoposition 5. Let $(X, \tau)$ be a connected representable separable complete metric space. If $\tau$ does not have a base of totally disconnected sets, then $(X, \tau)$ is locally connected.

With respect to the above proposition it is noteworthy that a connected locally compact Hausdorff space cannot have a base of totally disconnected sets. It is possible to modify the Cantor's teepee [9, Example 129] in order to obtain a separable connected metric space $(X, \tau)$ such that $\tau$ has a base of totally disconnected sets; however, so far as we know, the following question is unanswered.

Does there exist a homogeneous connected complete metric space $(X, \tau)$ such that $\tau$ has a base of totally disconnected sets? In particular can such a space be representable?

\section{REFERENCES}

1. R. D. Anderson and R. H. Bing, A complete elementary proof that Hilbert space is homeomorphic to the countable infinite product of lines, Bull. Amer. Math. Soc., 74 (1968), 771-792.

2. R. Bennett, Countable dense homogeneous spaces, Fund. Math., 74 (1972), 189-194.

3. P. Duvall, P. Fletcher, and R. A. McCoy, Isotopy Galois spaces, Pacific J. Math., 45 (1973), 435-442.

4. B. Fitzpatrick, Jr., A note on countable dense homogeneity, Fund. Math., 75 (1972), $33-34$.

5. P. Fletcher, Note on quasi-uniform spaces and representable spaces, Colloq. Math., 23 (1971), 263-265.

6. P. Fletcher and R. A. McCoy, Galois spaces, representable spaces and strongly locally homogeneous spaces, Fund. Math., 73 (1972), 85-91. 
7. L. R. Ford, Jr., Homeomorphism groups and coset spaces, Trans. Amer. Math. Soc., 77 (1954), 490-497.

8. J. de Groot, Topological Hilbert space and the drop-out effect $\mathrm{zw}$-1969, Mathematisch Centrum.

9. L. A. Steen and J. A. Seebach, Jr., Counterexamples in Topology, Holt, Rinehart and Winston, Inc., 1970.

Received February 1, 1973.

Virginia Polytechnic Institute and State University 



\section{PACIFIC JOURNAL OF MATHEMATICS}

\section{EDITORS}

RICHARD ARENS (Managing Editor)

University of California

Los Angeles, California 90024
J. DUGUNDJI*

Department of Mathematics

University of Southern California

Los Angeles, California 90007

D. Gilbarg and J. Milgram

Stanford University

Stanford, California 94305
University of Washington

Seattle, Washington 98105

ASSOCIATE EDITORS
E. F. BECKENBACH
B. H. NeumanN
F. WoLF
K. YosHIDA

\section{SUPPORTING INSTITUTIONS}

\author{
UNIVERSITY OF BRITISH COLUMBIA \\ CALIFORNIA INSTITUTE OF TECHNOLOGY \\ UNIVERSITY OF CALIFORNIA \\ MONTANA STATE UNIVERSITY \\ UNIVERSITY OF NEVADA \\ NEW MEXICO STATE UNIVERSITY \\ OREGON STATE UNIVERSITY \\ UNIVERSITY OF OREGON \\ OSAKA UNIVERSITY
}

\author{
UNIVERSITY OF SOUTHERN CALIFORNIA \\ STANFORD UNIVERSITY \\ UNIVERSITY OF TOKYO \\ UNIVERSITY OF UTAH \\ WASHINGTON STATE UNIVERSITY \\ UNIVERSITY OF WASHINGTON
* * * *
AMERICAN MATHEMATICAL SOCIETY \\ NAVAL WEAPONS CENTER
}

The Supporting Institutions listed above contribute to the cost of publication of this Journal, but they are not owners or publishers and have no responsibility for its content or policies.

Mathematical papers intended for publication in the Pacific Journal of Mathematics should be in typed form or offset-reproduced, (not dittoed), double spaced with large margins. Underline Greek letters in red, German in green, and script in blue. The first paragraph or two must be capable of being used separately as a synopsis of the entire paper. Items of the bibliography should not be cited there unless absolutely necessary, in which case they must be identified by author and Journal, rather than by item number. Manuscripts, in duplicate if possible, may be sent to any one of the four editors. Please classify according to the scheme of Math. Rev. Index to Vol. 39. All other communications to the editors should be addressed to the managing editor, or Elaine Barth, University of California, Los Angeles, California, 90024.

100 reprints are provided free for each article, only if page charges have been substantially paid. Additional copies may be obtained at cost in multiples of 50 .

The Pacific of Journal Mathematics is issued monthly as of January 1966. Regular subscription rate: $\$ 72.00$ a year (6 Vols., 12 issues). Special rate: $\$ 36.00$ a year to individual members of supporting institutions.

Subscriptions, orders for back numbers, and changes of address should be sent to Pacific Journal of Mathematics, 103 Highland Boulevard, Berkeley, California, 94708.

PUBLISHED BY PACIFIC JOURNAL OF MATHEMATICS, A NON-PROFIT CORPORATION

Printed at Kokusai Bunken Insatsusha (International Academic Printing Co., Ltd.), 270, 3-chome Totsuka-cho, Shinjuku-ku, Tokyo 160, Japan.

* C. R. DePrima California Institute of Technology, Pasadena, CA 91109, will replace J. Dugundji until August 1974.

Copyright (C) 1973 by Pacific Journal of Mathematics

Manufactured and first issued in Japan 


\section{Pacific Journal of Mathematics}

\section{Vol. 51, No. $2 \quad$ December, 1974}

Robert F. V. Anderson, Laplace transform methods in multivariate spectral theory .................................................. 339

William George Bade, Two properties of the Sorgenfrey plane . . . . . . . . . . . . 349

John Robert Baxter and Rafael Van Severen Chacon, Functionals on continuous

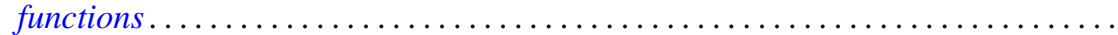

Phillip Wayne Bean, Helly and Radon-type theorems in interval convexity

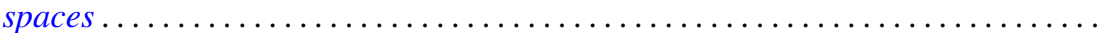

James Robert Boone, On k-quotient mappings $\ldots \ldots \ldots \ldots \ldots \ldots \ldots \ldots \ldots$

Ronald P. Brown, Extended prime spots and quadratic forms . . . . . . . . . . . .

William Hugh Cornish, Crawley's completion of a conditionally upper continuous lattice .............................................

Robert S. Cunningham, On finite left localizations ...................

Robert Jay Daverman, Approximating polyhedra in codimension one spheres

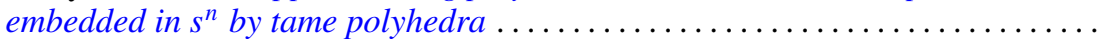

Burton I. Fein, Minimal splitting fields for group representations . . . . . . . . . . . .

Peter Fletcher and Robert Allen McCoy, Conditions under which a connected

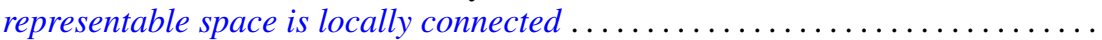

Jonathan Samuel Golan, Topologies on the torsion-theoretic spectrum of a noncommutative ring...

Manfred Gordon and Edward Martin Wilkinson, Determinants of Petrie matrices.

Alfred Peter Hallstrom, A counterexample to a conjecture on an integral condition for determining peak points (counterexample concerning peak points)........

E. R. Heal and Michael Windham, Finitely generated $F$-algebras with applications to Stein manifolds.

Denton Elwood Hewgill, On the eigenvalues of a second order elliptic operator in an unbounded domain ............................

Charles Royal Johnson, The Hadamard product of $A$ and $A^{*}$.

Darrell Conley Kent and Gary Douglas Richardson, Regular completions of Cauchy spaces.

Alan Greenwell Law and Ann L. McKerracher, Sharpened polynomial approximation

Bruce Stephen Lund, Subalgebras of finite codimension in the algebra of analytic functions on a Riemann surface. .

Robert Wilmer Miller, TTF classes and quasi-generators . .

Roberta Mura and Akbar H. Rhemtulla, Solvable groups in which every maximal partial order is isolated ....

Isaac Namioka, Separate continuity and joint continuity...

Alan Saleski, Entropy of self-homeomorphisms of statistical pseudo-metric

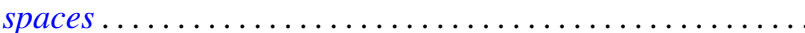

H. A. Seid, Cyclic multiplication operators on $L_{p}$-spaces .....

H. B. Skerry, On matrix maps of entire sequences ............

John Brendan Sullivan, A proof of the finite generation of invariants of a normal

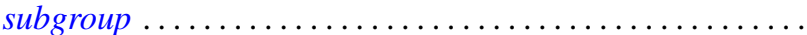

John Griggs Thompson, Nonsolvable finite groups all of whose local subgroups are

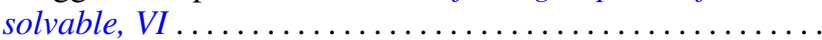

